\title{
Letter to the Editor: Cancer rates not explained by smoking: how to investigate a single county
}

\author{
Douglas J. Myers ${ }^{1 *}$, Polly Hoppin², Molly Jacobs², Richard Clapp ${ }^{2}$ and David Kriebel ${ }^{2}$
}

To the Editor:

We recently published "Cancer rates not explained by smoking: a county-level analysis" in your journal [1]. Using U.S. Surveillance, Epidemiology and End Results (SEER) cancer incidence and population data for 612 counties [2], we simulated the expected effect of eliminating smoking on the rates of 12 types of cancer known to be caused by smoking [3]. We estimated that in 2016, $39.8 \%$ of the cancer incidence of these 12 types would not have occurred had smoking been eliminated. Conversely, about $60 \%$ of these cancers would still occur, even in the absence of smoking. This finding is in good agreement with previously published estimates of the "attributable fraction" of cancer due to smoking [4].

A novel finding from our county-level approach was that there would be considerable variability in the benefit of smoking elimination; and in particular that some counties would benefit only modestly from the "best case" scenario of tobacco control. We found that under this scenario, SEER counties whose cancer incidence of the 12 smoking-related types would decline by less than $10 \%$ were in the metropolitan areas of large cities such as Detroit MI, Louisville KY and New Orleans LA.

Following a symposium on cancer and environment in Pittsburgh PA in $2019^{1}$, we were asked by public health

\footnotetext{
${ }^{1}$ https://sites.google.com/silentspring.org/cancer-environmentpasymposium/home

* Correspondence: douglasmyers@boisestate.edu

'Department of Community and Environmental Health, College of Health Sciences, Boise State University, 1910 University Drive, Idaho 83725 Boise, USA

Full list of author information is available at the end of the article
}

and community leaders to apply this analysis to their county, Allegheny. The Pittsburgh region has long suffered from elevated levels of air pollution, and members of the public are concerned about the risk it poses to public health.

Allegheny County is not in SEER, so additional analyses were needed to answer this question. Here we describe briefly how we applied our analysis of hypothetical smoking elimination to a specific non-SEER county. In the online supplement, we provide a step-by-step summary of the method and the key computer code, in STATA [5], to allow others to investigate their county, whether or not it is in SEER. We demonstrate using the method with lung cancer alone rather than with the set of 12 smoking-related types that were the focus of our paper; in practice, any set of cancers could be used.

We obtained the counts of lung cancers in Allegheny County by age and gender from the PA Cancer Registry ${ }^{2}$, and population data from the US Census Bureau for 2016. Smoking data were available from Institute for Health Metrics and Evaluation (IHME) [6]. We chose to lag smoking by 20 years, the most commonly applied lag for smoking and lung cancer, although other lags could have been chosen. We fit the same multi-level mixed-effects regression model described in our paper [1] to the augmented dataset of 613 counties (SEER + Allegheny). This allowed us to estimate the 2016 incidence rate of lung cancer under the scenario of complete smoking elimination for the last 20 years.

\footnotetext{
${ }^{2}$ These data were provided by the Pennsylvania Department of Health. The Department specifically disclaims responsibility for any analyses, interpretations or conclusions.
} 
As expected, smoking elimination would have had a substantial effect on lung cancer incidence across the SEER counties in 2016, with an average reduction of $62 \%$, consistent with tobacco's well-known status as the predominant cause of lung cancer. However, the model predicts a substantial variation in this reduction from county to county; the top $5 \%$ of counties would experience a reduction greater than $80 \%$, while the bottom $5 \%$ would see a reduction of less than $15 \%$ in lung cancer incidence from smoking elimination. Allegheny County is in this latter category: the model estimated that Allegheny County's lung cancer rate would have dropped by only $11 \%$, meaning less benefit in terms of reduced lung cancer rates than in all but $2 \%$ of SEER counties.

Communities often want to know "why is our cancer rate elevated?" Epidemiology is frequently unable to provide clear answers to this question because of small numbers, difficulties characterizing historical exposures for long latency diseases, and other wellknown pitfalls of cluster investigations [7]. The analyses described here do not answer this basic question, but may help move past a frequent sticking point in local discussions. A common response from authorities is that smoking is the single most important cause of cancer, particularly for lung cancer, with the implication that environmental risk factors should not be priority concerns. This is despite known environmental and occupational causes of lung cancer, including urban air pollution [8] and dozens of industrial chemicals in occupational settings [9].

The ranking of Allegheny County in the bottom $2 \%$ of SEER counties with regard to the benefit of tobacco control for lung cancer raises a red flag about past and ongoing exposures that may increase cancer risk. Indeed, in Allegheny County, radon is of concern, as are pollutants known to cause lung and other types of cancer which are emitted from manufacturing (coke ovens are a particular concern in Pittsburgh) and mobile sources, at levels that put residents at higher risk than in most other counties in the country [10].

Our recently-published paper established a method for identifying counties where public health authorities should be particularly attuned to risk factors for cancer other than tobacco, in addition to their ongoing efforts to reduce smoking [1]. The attached Supplement describes methods for identifying these counties. As noted in the original manuscript, a limitation of this approach is the lack of individual-level smoking data (we refer readers to the manuscript for additional discussion of limitations) [1]. In the context of environmental justice, this approach may assist public health, environmental and community leaders in addressing disparate burdens of exposures among counties. Where counties or communities are still exposed to carcinogens in air, water and workplaces, we encourage aggressive investment in reducing exposure and promoting safer alternatives as essential pathways for cancer prevention.

\section{Abbreviations}

SEER: Surveillance, Epidemiology and End Results

\section{Supplementary information}

The online version contains supplementary material available at https://doi. org/10.1186/s12940-021-00737-8.

Additional file 1 Supplementary material

Acknowledgements

Not applicable.

Authors' contributions

Conception and design: DM, PH, MJ, RC, DK. Development of methodology: DM and DK. Analysis of data (e.g., statistical analysis, biostatistics,

computational analysis): DM and DK. Interpretation of findings: DM, PH, MJ, RC, DK. Writing, review, and/or revision of the manuscript: DM, PH, MJ, RC, DK. The author(s) read and approved the final manuscript.

Authors' information (optional)

Not applicable.

\section{Funding}

Dr. Hoppin's and Ms. Jacobs' work on this paper was supported in part by a grant from the Heinz Endowments. The funders had no role in the study design, data collection, data analysis, data interpretation, or the writing of the report.

Availability of data and materials

Dataset analyzed during the current study is publicly available at the Surveillance, Epidemiology and End Results Program (SEER) repository, https://seer.cancer.gov/data/.

\section{Declarations}

Ethics approval and consent to participate

Because all data were publicly available and not personally identifiable, Institutional Review Board approval was not required.

Consent for publication

Not applicable.

\section{Competing interest}

The authors declare no competing interests.

\section{Author details}

${ }^{1}$ Department of Community and Environmental Health, College of Health Sciences, Boise State University, 1910 University Drive, Idaho 83725 Boise, USA. 'Lowell Center for Sustainable Production, University of Massachusetts, Lowell 1 University Avenue, 01854 Lowell, MA, USA.

Received: 29 January 2021 Accepted: 25 April 2021

Published online: 21 May 2021

\section{References}

1. Myers DJ, Hoppin P, Jacobs M, Clapp R, Kriebel D. Cancer rates not explained by smoking: a county-level analysis. Environ Health. 2020. DOI: https://doi.org/10.1186/s12940-020-00613-x. 19: 64. Published online 2020 Jun 6.

2. Howlader NNA, Krapcho M, Miller D, Brest A, Yu M, Ruhl J, Tatalovich Z, Mariotto A, Lewis DR, Chen HS, Feuer EJ, Cronin KA, editors. SEER Cancer 
Statistics Review (CSR), 1975-2016 Bethesda; 2019. Available from: https:// seer.cancer.gov/csr/1975_2018/, based on November 2018 SEER data submission, posted to the SEER web site, April 2019. Accessed 4 December 2020.

3. Gallaway MS, Henley SJ, Steele CB, Momin B, Thomas CC, Jamal A, et al. Surveillance for Cancers Associated with Tobacco Use - United States, 2010 2014. MMWR Surveill Summ. 2018;67(12):1-42.

4. Islami F, Goding Sauer A, Miller KD, Siegel RL, Fedewa SA, Jacobs EJ, et al. Proportion and number of cancer cases and deaths attributable to potentially modifiable risk factors in the United States. CA Cancer J Clin. 2018:68(1):31-54.

5. StataCorp. Stata Statistical Software: Release 16. College Station. TX: StataCorp LLC; 2019.

6. Dwyer-Lindgren L, Mokdad AH, Srebotnjak T. et al. Cigarette smoking prevalence in US counties: 1996-2012. Popul Health Metrics 2014;12(5). https://doi.org/10.1186/1478-7954-12-5.

7. Elliott P, Wartenberg D. Spatial Epidemiology: Current Approaches and Future Challenges. Environ Health Perspect. 2004;112:998-1006. DOl:https:// doi.org/10.1289/ehp.6735.

8. International Agency for Research on Cancer. Outdoor Air Pollution. IARC Monographs on the Identification of Carcinogenic Risks to Humans Volume 109. France: Lyon; 2016.

9. GBD 2016 Occupational Carcinogens Collaborators. Global and regional burden of cancer in 2016 arising from occupational exposure to selected carcinogens: a systematic analysis for the Global Burden of Disease Study 2016. Occup Environ Med. 2020;77(3):151-9. https://doi.org/10.1136/ oemed-2019-106012.

10. U.S. Environmental Protection Agency. National Air Toxic Assessment. https://www.epa.gov/national-air-toxics-assessment. Accessed 4 December 2020

\section{Publisher's Note}

Springer Nature remains neutral with regard to jurisdictional claims in published maps and institutional affiliations.

Ready to submit your research? Choose BMC and benefit from:

- fast, convenient online submission

- thorough peer review by experienced researchers in your field

- rapid publication on acceptance

- support for research data, including large and complex data types

- gold Open Access which fosters wider collaboration and increased citations

- maximum visibility for your research: over $100 \mathrm{M}$ website views per year

At $\mathrm{BMC}$, research is always in progress.

Learn more biomedcentral.com/submissions 